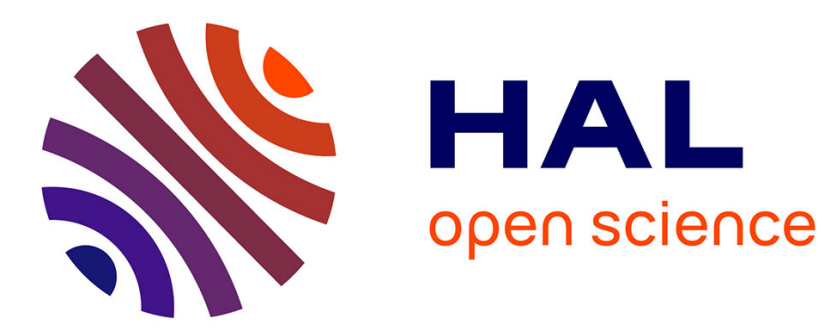

\title{
Transmission electron microscopy study of quartz single crystals deformed at room temperature and atmospheric pressure by indentations
}

L. Trépied, J.C. Doukhan

\section{- To cite this version:}

L. Trépied, J.C. Doukhan. Transmission electron microscopy study of quartz single crystals deformed at room temperature and atmospheric pressure by indentations. Journal de Physique Lettres, 1982, 43 (3), pp.77-81. 10.1051/jphyslet:0198200430307700 . jpa-00232012

\section{HAL Id: jpa-00232012 https://hal.science/jpa-00232012}

Submitted on 1 Jan 1982

HAL is a multi-disciplinary open access archive for the deposit and dissemination of scientific research documents, whether they are published or not. The documents may come from teaching and research institutions in France or abroad, or from public or private research centers.
L'archive ouverte pluridisciplinaire HAL, est destinée au dépôt et à la diffusion de documents scientifiques de niveau recherche, publiés ou non, émanant des établissements d'enseignement et de recherche français ou étrangers, des laboratoires publics ou privés. 
Classification

Physics Abstracts

$62.20 \mathrm{M}-81.40 \mathrm{~L}-61.70 \mathrm{~J}$

\title{
Transmission electron microscopy study of quartz single crystals deformed at room temperature and atmospheric pressure by indentations $(*)$
}

\author{
L. Trépied and J. C. Doukhan \\ Laboratoire de Structure et Propriétés de l'Etat Solide $(* *)$, \\ Université des Sciences et Techniques de Lille, 59655 Villeneuve d'Ascq Cedex, France \\ (Reçu le 19 octobre 1981, accepté le ler décembre 1981)
}

\begin{abstract}
Résumé. - La déformation plastique de quartz synthétiques monocristallins a été effectuée par microindentations. Dans ces conditions, la déformation est localisée dans une zone de quelques $[\mu \mathrm{m}]^{3}$ autour de l'indentation. Des observations en microscopie électronique à transmission mettent en évidence que des dislocations sont nuclées et glissent sous l'effet de la haute contrainte appliquée par l'indenteur. Les systèmes de glissement observés sont : $\langle\overline{1} 2 \overline{1} 0\rangle\{10 \overline{1} 0\},\langle\overline{1} 2 \overline{1} 0\rangle(0001)$ et [0001] $\{\overline{1} 2 \overline{1} 0\}$. De plus des défauts plans sont parallèles à $\{10 \overline{1} 0\}$ et $\{10 \overline{1} 1\}$. Leur contraste est cohérent avec celui de macles du Dauphiné. Bien qu'elles soient créées par la contrainte appliquée, ces macles ne contribuent pas à la déformation qui est accommodée seulement par le glissement des dislocations.
\end{abstract}

\begin{abstract}
Plastic deformation at room temperature of quartz single crystals has been carried out by means of microindentations. TEM observations of the indented zones clearly show that dislocations are nucleated and glide over a few microns under the high applied stress of the indentor. The following glide systems have been observed : $\langle\overline{1} 2 \overline{1} 0\rangle\{10 \overline{1} 0\},\langle\overline{1} 2 \overline{1} 0\rangle(0001)$ and $[0001]\{\overline{1} 2 \overline{1} 0\}$. Furthermore planar defects parallel to $\{10 \overline{1} 0\},\{10 \overline{1} 1\}$ and (0001) are also observed. Their fringe contrast is coherent with Dauphiné twins.
\end{abstract}

1. Introduction. - Many works have been carried out on the indentation of quartz crystals [1-4]. The aim of these earlier studies was mainly to determine the influence of physical parameters (such as temperature, impurity content, environment...) on quartz hardness. Few results deal with the plastic deformation mechanisms involved during these indentation experiments leading to unsolved questions. First of all, does the high confining pressure associated with the indentation process produce a local phase transformation to coesite as suggested (and nullified) by Brace [2] ? Secondly is quartz ductile or not during room temperature indentation, i.e. can dislocations be nucleated and can they glide ? If they can be nucleated, what are the active glide systems at room temperature ?

$\left.{ }^{*}\right)$ This paper is part of the thesis of L. Trépied.

$\left.{ }^{* *}\right)$ Associated to C.N.R.S. $\mathrm{n}^{\circ} 234$. 
Moreover, these experiments involving plastic deformation (as shown below) at room temperature prevent any (thermally activated) diffusion processes which are known to play a key role in the high temperature plasticity of quartz [5]. On the other hand the knowledge of the glide systems (if they do exist) activated at low temperature is of a crucial interest in geology.

The aim of the present study is to answer these questions. We have microindented a quartz single crystal of a rather high $[\mathrm{OH}]$ content $\left({ }^{1}\right)$ at room temperature and at atmospheric pressure on the faces $(0001)(10 \overline{1} 0)$ and $(\overline{1} 2 \overline{1} 0)$. These experiments lead to an easy and rapid determination of the properties of the involved dislocations (glide systems-preferred orientations). Experimental methods are identical to those reported by N. Doukhan [6] in her study of the room temperature plasticity of $\mathrm{MgAl}_{2} \mathrm{O}_{4}$ spinels. We have then observed the thin foils under an electron microscope equipped with a double tilt goniometer stage.

2. Results. - TEM observations of the indented foils $((10 \overline{1} 0)(0001)$ and $(\overline{1} 2 \overline{1} 0))$ always show the same features, i.e. occurrence of microfractures identified by Moiré fringe patterns, planar defects and dislocations. We describe now briefly these observations on each foil.

$2.1(10 \overline{1} 0)$ INDENTED FOIL. - Figure 1 is typical of an indent on such a face. It is surrounded by microfractures, dislocation loops and twin boundaries with their typical fringe patterns. From diffraction contrast experiments (the fringe contrast nearly vanishes for $\{1 \overline{1} 00\}$ reflexions $[7,8])$ these twins have been characterized as Dauphine ones. The dislocation loops lie in the plane of the foil and have a Bürgers vector $1 / 3[\overline{1} 2 \overline{1} 0]$ in $(10 \overline{10})\left({ }^{2}\right)$. The loops exhibit marked prefer-

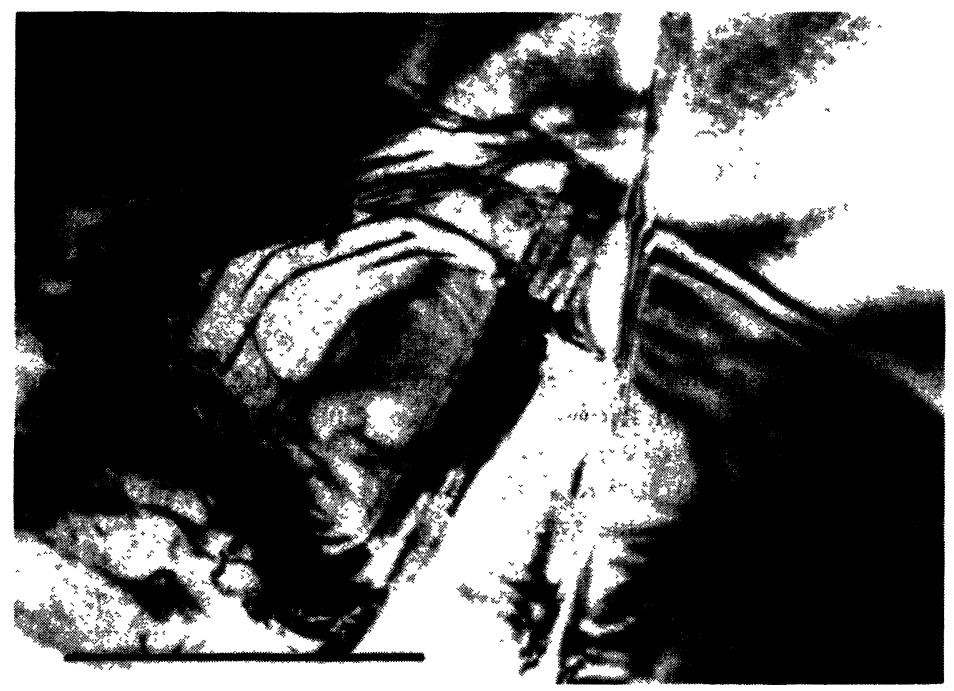

Fig. 1. - TEM micrograph of an indent on (1010). Dislocation loops (D), microfractures (F) (note the Moire fringes) and Dauphiné twins (T) are visible. $(10 \overline{1} 0)$ foil. $\bar{g}=1 \overline{1} 0 \overline{1}$. On this micrograph and on the others, the bar symbolizes $1 \mu \mathrm{m}$.

( $\left.{ }^{1}\right)$ This concentration measurement has been performed by S. H. Kirby (Menlo Park, U.S.A.) who is acknowledged for this courtesy. The $[\mathrm{OH}]$ content is of the order of $850 \mathrm{ppm}$. But we must keep in mind here (in the absence of any diffusion at room temperature) that this water content might have an opposite effect than during high temperature deformation, i.e. it could harden the crystal as any other impurity or at least be unefficient.

$\left(^{2}\right)$ Bürgers vectors are characterized with the usual criterion of no contrast for $\bar{g} \cdot \bar{b}=0$ which has been shown to work quite well to the case of quartz [9]. 
red orientations parallel to the direction $[\overline{1} 2 \overline{1} 0]$ (screw segments), $[\overline{1} 2 \overline{1} 3]$ and $[\overline{1} 2 \overline{1} \overline{3}]$. These directions are the ones already found when $\bar{a}$ prismatic glide $1 / 3\langle\overline{1} 2 \overline{1} 0\rangle\{1010\}$ is activated by compression at high temperature [10]. Therefore we assume that the observed dislocations have been nucleated by Frank Read sources acting in planes parallel to the (1010) foil under the indentor applied stress. The pyramid of the indentor when applied on the specimen gives rise to a rather complicated stress tensor [11]. However it is obvious that there is a non vanishing resolved shear stress in the foil plane. This stress must be high enough for the nucleation and the migration of dislocations in this foil plane. This is at least an argument to suggest that $\bar{a}$ prismatic glide is the easiest one at room temperature.

2.2 (0001) INDENTED FOIL. - For this orientation one also observes microfractures, Dauphiné twin boundaries which lie here in $\{10 \overline{10}\}$ and $\{10 \overline{1} 1\}$ planes and dislocations which are confined in a very narrow zone around the indent and with a very large density which prevents any possible Bürgers vector characterization. Figure 2 summarizes these features.

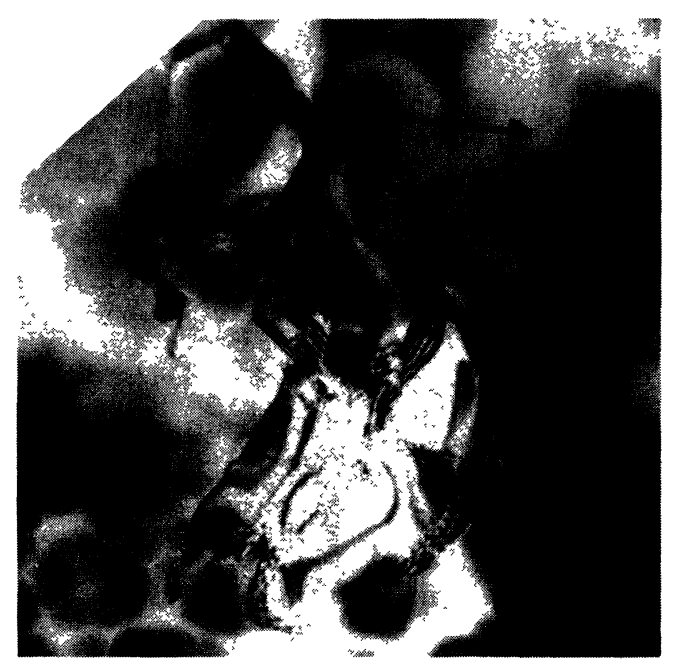

Fig. 2. - Indent on (0001). Twins (T) and microfractures (F) are present. Note in the centre of the indent the zone of high dislocation density (D). (0001) foil. $\bar{g}=10 \overline{1} 0$.

Comparing both experiments (indentation on (10 $\overline{1} 0)$ and (0001)), prismatic $\bar{a}$ glide is expected here, but $\{10 \overline{1} 0\}$ glide planes are now viewed edge on. This is a bad configuration to see the possible dislocation loops which would have developed in these planes (fractures also occur in planes perpendicular to (0001)). In contrast, in the basal plane which has the good orientation for easy dislocation characterization, the defects are highly concentrated in the central area and dislocation loops in the basal plane, if they do exist, have not spread out over similar distances as in the previous case. This observation is thus coherent with the above assumption that prismatic $\bar{a}$ glide is the easiest one at room temperature.

$2.3(\overline{1} 2 \overline{1} 0)$ INDENTED FOIL. - Figure 3 is typical of the deformation features observed in that case. One still observes microfractures, Dauphiné twins lying in non crystallographic planes and dislocations confined in a narrow zone around the indent. For an easier characterization of these dislocations another indented foil has been annealed for 15 hours at $850^{\circ} \mathrm{C}$ before ion thinning. This annealing process allowed the migration of the dislocations far enough from the indented zone to occur. Figure 4 shows an annealed indent. One mostly observes now large dis- 


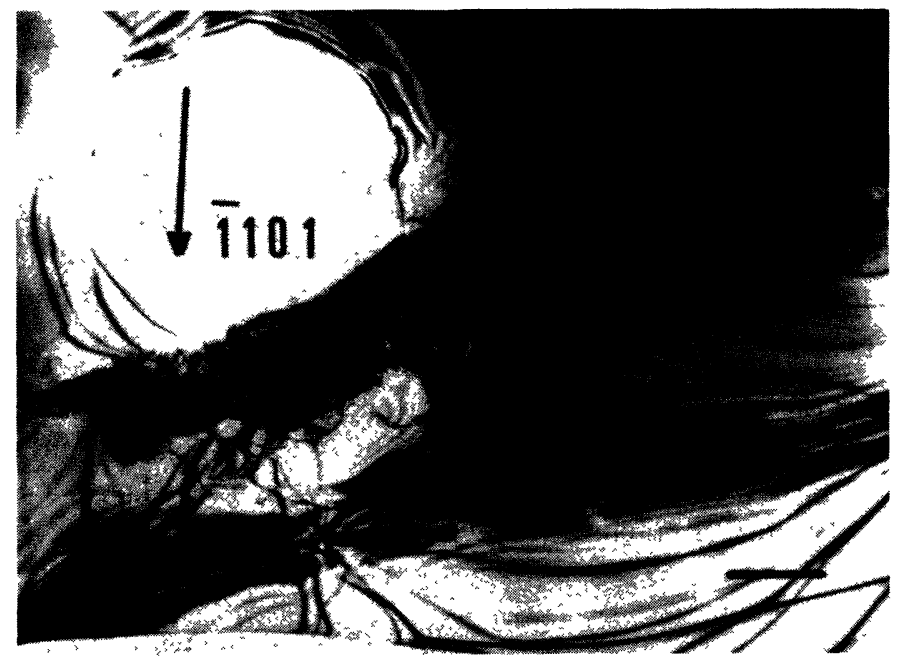

Fig. 3. - Indent on ( $\overline{1} 2 \overline{1} 0)$ same features as before (T.D.). (12 $\overline{1} 0)$ foil. $\bar{g}=\overline{1} 101$.

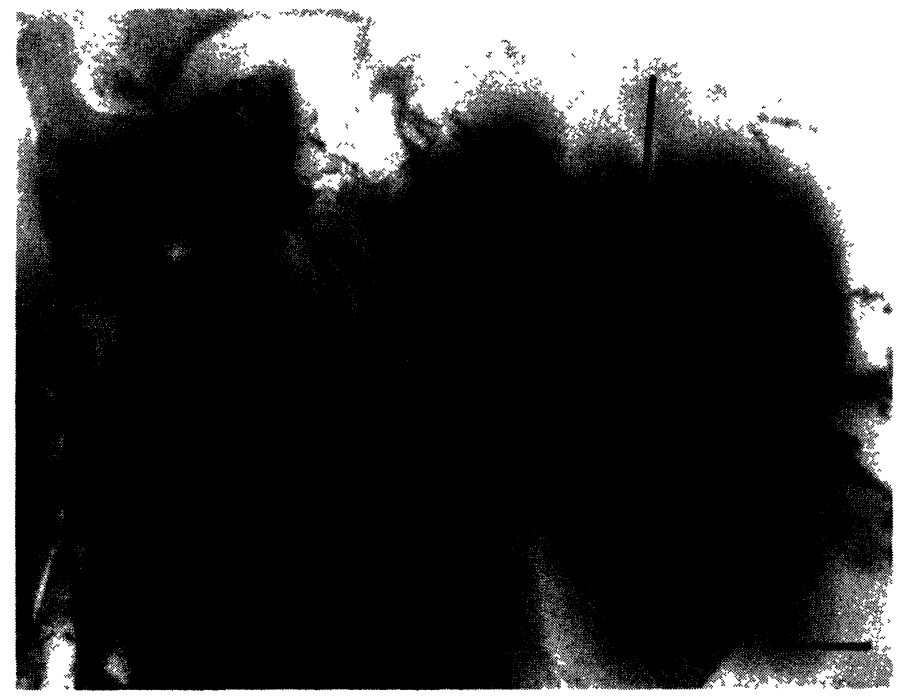

Fig. 4. - Indent on (12) 0 ). The sample has been annealed for 15 hours at $850^{\circ} \mathrm{C}$. Dislocation loops (D) are now well individualized. (F) and (T) also present. $(\overline{1} 2 \overline{1} 0)$ foil. $\bar{g}=\overline{1} 101$.

location loops in (0001) with $\bar{a}$ as Bürgers vector. There are also many loops of $\bar{c}$ dislocations lying in the plane of the foil and some loops of $\bar{a}$ dislocations in rhombohedral planes. Dauphiné twins have disappeared during the annealing process above the $\alpha-\beta$ transition temperature. New ones now lie in well defined crystallographic planes. However a possible memory effect can occur (reversible occurrence of Dauphiné twins during thermal cycles experiments). It has already been evidenced [12].

3. Discussion. - Some conclusions may be drawn from these observations. First of all, the brittle behaviour of quartz at room temperature is once more evidenced by the occurrence of many microfractures around the indents although the Vickers diamond was applied with a very 
low load $(0,1 N)$ progressively applied onto the sample surface. These fractures propagate over $10 \mu \mathrm{m}$ from the indent and no dislocations seem to be associated with them in contrast with previous observations of Schlössin [13] who saw etched dislocation loops (with segments parallel to $\langle\overline{a \pm c}\rangle)$ in front of crack tips. Secondly, we observe many Dauphiné twins. These defects are probably the ones already observed by Brace [2] and assigned by him as slip lines. In fact, our observations show that dislocations do not propagate over large distances. Many sources are activated in parallel planes and the resulting slip lines are short and tight and therefore very difficult to observe.

Thirdly in our experiments there is no new phase nucleated by the high confining pressure of the indentor (of the order of $20 \mathrm{kbar}$ after [2]). All our diffraction patterns on selected areas whatever their position relative to the indent always show the quartz symmetry. This result is not surprising if one recalls that the quartz-coesite transformation is a reconstructive one, its kinetics being probably governed by diffusion.

Lastly we could only characterize $\bar{a}$ prismatic glide $1 / 3\langle\overline{1} 2 \overline{1} 0\rangle\{10 \overline{1} 0\}$ after room temperature indentation. Other glide systems are certainly activated too, but the lattice frictions are so high for the corresponding dislocations that the latter ones are entangled in a very narrow zone around the indent and cannot be resolved even with current magnification available in TEM.

We have annealed an indented specimen in view to enlarge the dislocation loops and facilitate their characterization. During this heat treatment, the lattice frictions experienced by the various dislocation types are completely changed (i.e. their elastic limit). Therefore the corresponding observations are no more representative of the room temperature elastic limit hierarchy. The predominance of $\bar{a}$ basal loops after annealing suggests that at high temperature the elastic limit of $\bar{a}$ basal glide is the easiest one and that cross slip is an operative mechanism.

In conclusion we can point out that a limited amount of plastic deformation can be induced by room temperature indentation in quartz crystals. This plastic strain is mostly achieved by prismatic $\bar{a}$ glide. The corresponding elastic limit as deduced from the Vickers hardness is of the order of $30 \mathrm{kbar}$ (this value is very crude because of the numerous cracks associated to the indents). This elastic limit corresponds to a glide motion of dislocations not assisted by [OH] diffusion. However the exact role of $[\mathrm{OH}]$ in quartz is not elucidated [14-15] and at room temperature the fixed $[\mathrm{OH}]$ impurities could have a hardening effect. Experiments on quartzes with different $[\mathrm{OH}]$ content would be necessary to $\mathrm{f}$ recise this point.

\section{References}

[1] Westbrook, J. H., J. Am. Ceram. Soc. 41 (1958) 433-440.

[2] BRACE, W. F., J. Geol. 71 (1963) 581-595.

[3] Nadeau, J. S., J. Am. Ceram. Soc. 53 (1970) 568-573.

[4] Hartley, N. E. W., Wilshaw, T. R., J. Mat. Sci. 8 (1973) 265-278.

[5] Kirby, S. H., McCormick, J. W., Bull. Mineral. 102 (1979) 124-137.

[6] Doukhan, N., J. Physique Lett. 40 (1979) L-603-L-606.

[7] McLaren, A. C., Phakey, P. P., Phys. Status Solidi 31 (1969) 723-737.

[8] Van Tendeloo, G., Van Landuyt, J., Amelinckx, S., Phys. Status Solidi a 33 (1976) 723-735.

[9] Ardell, A. J., Christie, J. M., McCormick, J. W., Philos. Mag. 29 (1974) 1399-1411.

[10] Trepied, L., Doukhan, J. C., In preparation.

[11] LEE, D., in The science of hardness testing and its research applications, ed. by Westbrook, J. H. and Conrad, H., Amer. Soc. for Metals. Metals Park, Ohio 1973, p. 147-166.

[12] Bertagnolli, E., Kittinger, E., Tichy, J., J. Physique Lett. 39 (1978) L-295-L-297.

[13] Schlossin, H. H., Philos. Mag. 12 (1965) 467-478.

[14] Griggs, D. T., Geophys. J. R. Astron. Soc. 14 (1967) 19-31.

[15] Hirsch, P. B., J. Physique Colloq. 42 (1981) C3-149-C3-160. 